REVIEW

ARTICLE

\title{
Altered pharmacology in the intensive care unit patient
}

\author{
Giovanni Zagli $^{\mathrm{a} *}$, Francesca Tarantini ${ }^{\mathrm{a}}$, Manuela Bonizzoli ${ }^{\mathrm{b}}$, Alessandro Di \\ Filippo $^{a}$, Adriano Peris ${ }^{b}$, Angelo Raffaele De Gaudio ${ }^{a}$, Pierangelo Geppetti ${ }^{a}$ \\ ${ }^{\mathrm{a}}$ Department of Critical Care Medicine and Surgery, University of Florence and Azienda Ospedaliero-Universitaria Careggi, \\ Florence, Italy \\ ${ }^{\mathrm{b}}$ Intensive Care Unit of Emergency Department, University of Florence and Azienda Ospedaliero-Universitaria Careggi, \\ Florence, Italy
}

\section{Keywords \\ intensive care unit, \\ pharmacokinetic, \\ pharmacology, \\ sepsis, \\ trauma}

Received 9 November 2007; revised 4 February 2008; accepted 13 June 2008

\begin{abstract}
A B S TR A C T
Critically ill patients, not infrequently present alterations of physiological parameters that determine the success/failure of therapeutic interventions as well as the final outcome. Sepsis and polytrauma are two of the most common and complex syndromes occurring in Intensive Care Unit (ICU) and affect drug absorption, disposition, metabolism and elimination. Pharmacological management of ICU patients requires consideration of the unique pharmacokinetics associated with these clinical conditions and the likely occurrence of drug interaction. Rational adjustment in drug choice and dosing contributes to the appropriateness of treatment of those patients.
\end{abstract}

${ }^{\star}$ Correspondence and reprints: giovanni.zagli@unifi.it

\section{INTRODUCTION}

Care of critically ill patients requires frequent adjustments of therapy based on clinical conditions and intervening pathophysiological modifications which affect pharmacokinetics.

Sepsis and polytrauma are two of the most lifethreatening conditions seen in Intensive Care Unit (ICU), both involving significant modifications of organ-specific and systemic homeostasis. The management of patients with sepsis is difficult as underlined by the EURICUS studies that describe the critical role of the length of stay (LOS) for the development of organ failure, with an high impact on mortality rate after discharge from the ICU $[1,2]$. Indeed, sepsis can occur in critically ill patients as a nosocomial infection, often related with the duration of hospitalization. Sepsis is defined as a systemic inflammatory response syndrome (SIRS) to a proved (or suspected) infection, that results in the alteration of the coagulation system and the microcirculation, with failure of organs/tissues perfusion, and dysregulation of the immune system [3-5]. In severe sepsis or septic shock, pathophysiological changes partially or completely modify pharmacokinetic parameters, resulting in an escalating approach to the number and, often, dosing of administered drugs [6].

The systemic inflammatory response, commonly seen in patients with major trauma (MT), is induced and sustained by the ensuing cascade of inflammatory mediators, which can determine flow-misdistribution and peripheral hypoperfusion [7]. The extent of inflammation in patients with trauma markedly varies according to the type of injury; bacterial or fungal colonization of wounded organs may result in severe infection, sepsis, and septic shock.

Currently, the most relevant therapeutic interventions in ICU are targeted to the prevention of organ failure, limitation of adverse reactions and LOS. In this perspective, rational drug adjustments, based on pharmacokinetic and pharmacodynamic changes that characterize sepsis or MT, often dictate the outcome of a critically ill patient. The changed physiology and, consequently, the pharmacokinetic parameters, could indeed alter the efficacy and the safety of drugs at the dosage usually 
prescribed, potentially producing side-effects and/or therapeutic failure.

\section{PATHOPHYSIOLOGY OF SEPSIS}

The definition of sepsis includes suspected or demonstrated infection, in a patient with clinical signs of SIRS (fever or hypothermia, bradycardia or tachycardia, tachypnea, leukocytosis or leucopenia or circulating immature forms) [3]. Sepsis is classified as severe when induces organ dysfunction or tissue hypoperfusion, whereas septic shock is the evolution of severe sepsis, with systemic hypoperfusion [8]. Septic shock and multiorgan failure (MOF) are the most common causes of death in patients with sepsis. Mortality rate associated with severe sepsis is up to $30 \%$, with a pick of $70 \%$ for septic shock [6,9-11].

Sepsis is characterized by a complex, and still not completely understood, interaction between the immune system (innate and adaptive), the coagulation system, inflammatory mediators, and microorganisms [4-6]. Thus, sepsis can be defined as a maladaptive response of the host to a bacterial-fungal-viral infection, the severity of which depends both from the pre-morbid health condition of the host and the virulence of the microorganism involved.

In the initial phase of the host-microorganism interaction, the innate immune system plays a pivotal role, mainly through the activation of toll-like receptors (TLRs) $[12,13]$ and subsequent synthesis and release of proinflammatory molecules, such as tumor necrosis factor $\alpha$ (TNF- $\alpha$ ), interleukin-6 (IL-6) and interleukin-1 $\beta$ (IL-1 $\beta$ ) (Table I). In sepsis, the increasing expression of procalcitonin (PCT) is considered a diagnostic and a prognostic marker, although its role in SIRS and sepsis has still to be clarified $[14,15]$ (Table I). PCT production is induced by bacterial lipopolysaccharide and pro-inflammatory cytokines in different cells, such as hepatocytes and human peripheral blood mononuclear cells $[16,17]$. As PCT, the expression of calcitonin gene-related peptide appears to be increased in SIRS and sepsis [18-20], suggesting an important role of this potent vasodilator agent [21], in refractory septic shock. Activation of neutrophils, monocytes/macrophages and lymphocytes produces injury to the endothelium, with development of increased endothelial permeability, accumulation of plasma proteins and fluids into the interstitium and in usually fluidfree anatomical cavities (e.g., pleural cavity) (Table I). Moreover, activation of endothelial cells leads to the production and release of nitric oxide (NO), one of the most
Table I Physiopathologic features of sepsis, major trauma and head trauma.

\begin{tabular}{|c|c|c|c|}
\hline & Sepsis & $\begin{array}{l}\text { Major } \\
\text { trauma }\end{array}$ & $\begin{array}{l}\text { Head } \\
\text { trauma }\end{array}$ \\
\hline $\begin{array}{c}\text { SIRS criteria } \\
\quad[3,37]\end{array}$ & Present & Present & May occur \\
\hline $\begin{array}{l}\text { Activation of innate immune } \\
\text { system } \\
{[3,37,44,45]}\end{array}$ & Yes & Yes & Yes \\
\hline $\begin{array}{c}\text { IL-1 } \beta, \text { IL-6, TNF- } \alpha \\
\text { over-production } \\
{[4,5,7,42]}\end{array}$ & Yes & Yes & Yes \\
\hline $\begin{array}{l}\text { PCT level increase } \\
\quad[14,15]\end{array}$ & Yes & May occur & May occur \\
\hline $\begin{array}{c}\text { Capillary leakage } \\
{[4,5,7,33,34]}\end{array}$ & Present & May occur & May occur \\
\hline $\begin{array}{l}\text { Coagulation and hemostasis } \\
\text { alteration } \\
{[4,5,7,30-32]}\end{array}$ & Yes & Yes & Yes \\
\hline $\begin{array}{l}\text { Interstitial edema } \\
\quad[4,5,7]\end{array}$ & Present & May occur & May occur \\
\hline $\begin{array}{c}\text { Release of NO } \\
{[4,5,7,40]}\end{array}$ & Yes & May occur & May occur \\
\hline $\begin{array}{l}\text { Mitochondrial dysfunction and } \\
\text { ATP production impairment } \\
{[5,7,27]}\end{array}$ & Yes & May occur & May occur \\
\hline $\begin{array}{l}\text { RNS and ROS over-production } \\
{[4,5,7,28,39,40]}\end{array}$ & Yes & Yes & Yes \\
\hline $\begin{array}{l}\text { Apoptosis } \\
{[4,5,7,25,26]}\end{array}$ & Yes & May occur & May occur \\
\hline $\begin{array}{l}\text { Cell lysis and necrosis } \\
{[4,5,7]}\end{array}$ & May occur & Yes & Yes \\
\hline
\end{tabular}

SIRS, systemic inflammatory response syndrome; PCT, procalcitonin; TNF- $\alpha$, tumor necrosis factor $\alpha$; IL-6, interleukin-6; IL-1 $\beta$, interleukin-1 $\beta$; NO, nitric oxide; RNS, reactive nitrogen species; ROS, reactive oxygen species.

potent vasodilator and a central player in the pathogenesis of septic shock [22] (Table I).

The immunosuppression associated with sepsis facilitates microorganism colonization and diffusion and is sustained by complex mechanisms, including the evolution of $\mathrm{T}$ lymphocytes from a Th1 phenotype (producing pro-inflammatory mediators), to a Th2 phenotype (producing anti-inflammatory cytokines) $[6,23]$. Decreased number of immune cells ( $\mathrm{T}$ and $\mathrm{B}$ lymphocytes, dendritic cells) by apoptosis has also been correlated with the activity of the disease [24] and the outcome [5,25,26]. Mitochondrial dysfunction, with failure to produce ATP, is also considered an important pathological features in multi-organ dysfunction $[5,7,27]$ (Table I).

The over-production of reactive nitrogen species (RNS) and reactive oxygen species (ROS), associated with a 
reduction or depletion of antioxidant defense systems (i.e., glutathione) of the host, also play a role in the pathogenesis of MOF [28,29] and the increase in procoagulant activity observed in sepsis [30] (Table I). The imbalance between coagulation and anti-coagulation systems is also supported by the suppression of antihemostatic factors induced by inflammatory mediators (IL-6, TNF- $\alpha$ ) [31]. Moreover, sepsis is characterized by a high consumption of protein $\mathrm{C}$, associated with low levels of protein S and antithrombin III [32]. The excess procoagulant activity is implicated in failure of microcirculation and consequent tissue hypoperfusion $[5,6,33]$. Endothelial dysfunction and microcirculation impairment have been directly correlated to multi-organ dysfunction syndrome (MODS) and clinical outcome [34].

\section{PATHOPHYSIOLOGY OF TRAUMA}

Major trauma is the first cause of death in young people $[7,35,36]$. Death can occur as a consequence of direct physical injury or late complications, such as infections (microbial colonization of exposed wounds) and/or organ failure.

The injury to organs, soft tissues and bones determines a host systemic inflammatory reaction which can be defined, as well as in sepsis, as SIRS [3,37] (Table I). Cell lysis results in the release of endogenous antigens which stimulate coagulation, complement cascade, and chemotaxis of circulating adaptive immune cells, with overactivation of leukocytes, monocytes/macrophages, and natural killer cells leading, in the most severe cases, to the development of MODS and MOF [7]. Bleeding and loss of tissues also contribute to the fall in the perfusion of organs.

An extensive injury results in massive production of TNF- $\alpha$, interferon (IFN)- $\gamma$, IL-1 $\beta$, IL- 6 as also adhesion molecules, acute phase proteins, arachidonic acid metabolites (Table I). Like in sepsis, the expression of PCT could raise in severe trauma [14] (Table I). Adhesion and accumulation of neutrophils, and other inflammatory cells, in the damaged tissue play a pivotal role in the development of secondary organ failure [38] through the over-production and activation of proteases, ROS and RNS $[7,39,40]$ (Table I).

In MT, blood loss can be an important pathological event. Hemorrhage can occur both through open-flesh wounds and/or through close fracture of bones (e.g., a severe pelvic bone fracture can determine an hemorrhagic flow of up to $5 \mathrm{~L}$ ). A profuse blood loss affects oxygen delivery and transportation of nutrients to the peripheral tissues. Intravascular volume support includes infusion of crystalloids and colloidal solutions [41] and, based on the estimated loss of blood volume, transfusions of erythrocytes, platelets and plasma, depending on the hemoglobin level and coagulation tests. The fall in arterial pressure, consequent to the blood loss, increases the production of endogenous vasoactive agents. The level of vasoconstriction observed in a trauma patient is higher than expected, as a consequence of the stress reaction to the injury; therefore, further stimulations, oriented to maintain a normal mean arterial pressure, can cause an excess of peripheral vasoconstriction with a fall in perfusion. Thus, microcirculation perfusion failure may derive directly from the blood loss and indirectly from the inflammation and the vasoconstriction induced by endogenous amines produced in the stress neurohormonal reaction [7].

\section{Pathophysiology of head trauma}

Special attention should be directed to patients with head trauma. A primary brain damage results from forces directly applied to the skull, leading to either focal or diffuse injury patterns, which could have a very poor prognosis. The injury to the brain induces an acute reaction in the cells of central nervous system (neurons, astrocytes, microglia), with the production of proinflammatory mediators and local inflammation [42] (Table I). Moreover, as a direct consequence of the trauma, the blood-brain barrier is interrupted and systemic inflammatory mediators produced by distant wounded body parts, can come in contact with the brain, starting an 'inflammatory communication' between the central nervous system (CNS) and the periphery. The secretion of cytokines and chemokines maintains the inflammatory response, with the development of a neurodegenerative disease of the brain and of spinal cord injury [43-46] (Table I). Several cytokines are involved in neuroinflammation, included IFN- $\gamma$, TNF- $\alpha$, IL- $1 \alpha$, IL-1 $\beta$, and IL-6 [42], that seems to have a neuroprotective role as well [47]. The release of proteases and the production of ROS contribute to damage the blood-brain barrier and to the development of cerebral inflammatory edema [48-50] (Table I).

\section{PHARMACOLOGICAL ADJUSTMENTS IN THE CRITICALLY ILL PATIENT}

As a consequence of the pathophysiological modifications that occur in patients with sepsis or MT, drug 
pharmacokinetics and pharmacodynamics may be heavily altered, with major concern for therapy management [51-53].

\section{Absorption and distribution}

Oral absorption could be critically compromised as a result of the impairment of gastrointestinal peristalsis. Moreover, patients with intestinal infection or ischemia often undergo parenteral nutrition. Cardiac failure could also impair the intestinal absorption of drugs, both for reduced perfusion of organ and congestion of the venous system [51,52]. Modifications of skin and muscle perfusion and variation in body water content, frequently alter the first part of the absorption curve of drugs administered by intramuscular, subcutaneous, or transdermal routes. At the present time, very few experimental data exist on pharmacokinetic changes of drugs in critically ill patients, and no evidence-based protocols are available to guide the physician.

Intravenous (i.v.) administration is the preferred route in ICU patients who often require invasive intravascular devices, such as central venous catheters. The i.v. route assures the highest biological availability of drugs, which is critical especially for antimicrobial agents [54,55], and allows rapid correction of the dosage, particularly important in patients who require hemodynamic support with vasoactive-inotrope agents [56].

\section{Role of nutraceutical interventions}

Recently, the importance of nutraceutical interventions has been emphasized [57-59]. Enteral nutrition should be preferred even in patients with impaired gastric emptying, in which prokinetic drugs and a correct body positioning can improve peristalsis [60,61]. Indeed, maintenance of the physiological bacterial flora has been related with the preservation and homeostasis of the gastrointestinal mucosa. Bacterial translocation has been found to be lower in critical patients receiving enteral nutrition, with the addition of omega-3 (eicosapentaenoic and docosahexaenoic) fatty acids, glutamine, antioxidants $[57,58,62]$, nucleotides, prebiotic and probiotic supplements [63], whereas the role of arginine supplements in sepsis is still controversial [64,65].

\section{Modification of the gastrointestinal system}

An intra-abdominal pressure (IAP) increase over $12 \mathrm{mmHg}$ should be considered pathological, and it has been defined as intra-abdominal hypertension (IAH) [66]. Risk-factors for the development of IAH include abdominal trauma, excess of fluid replacement, sepsis, mechanical ventilation (MV) with high positive endexpiratory pressure (PEEP), moderate to severe hypothermia, bleeding into the abdominal cavity, liver failure with ascites. The increased IAP interferes with venous return to the right heart and gut mucosa perfusion (with augmented risk of intestinal sepsis and malabsorption), and impairs portal vein flow to the liver. All these modifications might contribute to alter the pharmacokinetics of orally administered drugs. In addition, distribution of i.v. drugs may be altered by decreased plasma protein production (liver failure) and/or protein intake [53]. Moreover, pathologic IAP can contribute to kidney hypoperfusion with subsequent renal impairment and reduced drug clearance.

\section{Support to the circulation}

Maintenance of an adequate tissue perfusion is of paramount importance in critically ill patients, which often requires exogenous amines (norepinephrine, dobutamine), vasoconstrictor agents (vasopressin), and fluid replacement (colloids, crystalloids) [6]. The rate of infusion of vasoactive-inotrope agents should be continuously adjusted to guarantee a suitable peripheral perfusion, as desensitization and down-regulation of adrenergic receptors usually require a progressive increase in dosage [67]. However, high dosage or longterm hemodynamic support produces a prolonged vasoconstriction of the capillary bed. Consequently, the maintenance of an adequate cardiac output with amine support should be integrated with rational fluid replacement therapy, to avoid systemic hypoperfusion [41]. In fact, the impairment of tissue perfusion could interfere with drug pharmacokinetics in many ways: increase in tissue $\mathrm{pH}$, intestinal malabsorption, muscle-skin misdistribution. On the other hand, an excess of fluid replacement could induce a different set of complications: change in transportation and distribution of i.v. administered drugs because of hemodilution, decreased plasma protein binding rate, fluid shift in the so-called 'third space,' increase in IAP [53]. Based on these considerations, a need of prolonged hemodynamic support can heavily modify the results (in terms of efficacy and/or side-effects) of other pharmacological interventions.

\section{Effects of lung injury and mechanical ventilation}

ICU patients often require MV with PEEP support. PEEP is used to recruit or stabilize lung alveolar units, especially in situations like inhalation, post-contusive lung injury, Acute Lung Injury/Adult Respiratory Distress Syndrome (ALI/ARDS), Transfusion Related Lung 
Injury (TRALI), pneumonia. A correct management of ventilatory support includes weaning the patient from $\mathrm{MV}$ as soon as clinical conditions improve. Indeed, prolonged MV and longer ICU stay are related with the development of complications, such as ventilation associated pneumonia [68] and the polyneuropathy/myopathy of critically ill patient, known as 'critical illness' [69]. Artificial ventilation produces alteration of venous return to the hearth, cardiac output, renal and liver blood flow [70], with direct consequences on the pharmacokinetics of drugs administered [71]. The application of continuous pressure by PEEP on diaphragm and thoracic vessels causes impairment of abdominal perfusion of organ. Reduced splanchnic venous flow during PEEP ventilation interferes with the function of intestinal mucosa, and reduces the absorption of proteins and orally administered drugs [53].

Experimental data show that during MV, pulmonary lymphatic flow can be decreased, with consequent fluid shift in the interstitial space and increment of intrapulmonary shunt [72,73]. The importance of these phenomena in humans remains difficult to establish, but it could be supposed that the distribution of drugs might be influenced by both the extravascular fluid shift and the intra-pulmonary shunt, with a possible alteration in dose/effective concentration.

Sepsis, pneumonia, TRALI and pulmonary trauma may all result in ARDS, an acute inflammatory process of the lung $[74,75]$. Patients with ARDS should undergo MV based on small tidal volumes to avoid barotrauma, and to reduce the rate of alveolar stretching [76]. In these patients, the use of inhaled nitric oxide (NO) could be taken into consideration to produce bronchodilatation and to reduce pulmonary vascular resistance, with improvement of lung perfusion and, consequently, a better distribution of intravenously administered drugs [77].

\section{Hepatic metabolism and drug interactions}

Hepatic failure can occur as a consequence of decreased perfusion and oxygen delivery to the organ during severe sepsis/septic shock, or, in trauma patients, as a direct injury to the abdominal wall. Fall in liver function produces alteration in all phases of drug pharmacokinetic, mainly in drug transportation and metabolization.

Drug hepatic clearance is defined as the volume of blood which is cleared from the molecule per unit of time [78]. The liver participates to drug pharmacokinetic at multiple levels: transportation of the drug through the portal vein flow, control of the free fraction of drug in blood, metabolism of the molecule, and excretion through the bile ducts. All these steps could be altered in septic patients. The acute phase reaction to a stressful event produces a decrease in liver enzymatic activity because of the inhibitory effect of pro-inflammatory cytokines (IL-1 $\beta$, IL-6, TNF- $\alpha$ ) on cytochrome P450 [78]. On the contrary, it has been reported that in trauma patients, especially if severe head injury is present, liver metabolism of certain drugs (phenytoin, pentobarbital, lorazepam) may be increased $[53,79,80]$. Modification of portal vein flow, secondary to MV, could also decrease hepatic metabolization rate of drugs, especially of highhepatic-extraction molecules, whereas clearance of lowhepatic-extraction molecules is more dependent on liver enzymatic capacity and free plasmatic drug fraction $[52,53]$.

In critically ill patients, drug interaction should always be taken into account. Many classes of drugs, frequently prescribed in ICU, exert an inhibitory effect on cytochrome P450 [52,54,81]: proton-pump inhibitors used to prevent stress-related gastrointestinal bleeding [82]; antiepileptic drugs, which are commonly used in patients with head injury and documented electroencephalographic signs of secondary seizures [83]; antimicrobial agents such as macrolides, fluoroquinolones, and azole derivate antifungal agents $[54,84]$. Note that therapeutic hypothermia, employed to decrease neurological damage in patients recovering from a cardiac arrest, exert an inhibitory effect on cytochrome P450 as well [85].

\section{Renal excretion}

The renal clearance of drugs can be severely impaired in patients with sepsis, MT, cardiac failure, direct or secondary (acute tubular necrosis, myoglobinuria) renal injuries. Drug dose adjustments should be made to the amount of serum creatinine and to the 24-h clearance of creatinine. For antimicrobials (e.g., glycopeptides) or sedative drugs (e.g., benzodiazepine), frequent determinations of plasma concentrations are necessary. Adjustment of daily dosage of antimicrobials is also required in patients who undergo hemofiltration, like continuous veno-venous hemofiltration $(\mathrm{CVVH})$, based on predicted drug CVVH removal rate $[86,87]$.

\section{Perfusion failure, capillary leakage and modification of distribution volume}

Peripheral ischemia/hypoxia in critically ill patients produces a reduction in tissue $\mathrm{pH}$ and endothelium damage. Tissue $\mathrm{pH}$ leans towards acidity largely because of an increased anaerobic metabolism of the cells, 
following oxygen delivery failure, with glucose conversion into ATP through the anaerobic glycolytic pathway, with the production of lactic acid. The pharmacokinetic and pharmacodynamic modifications that follow a $\mathrm{pH}$ change, have not been studied extensively. However, for drugs that are weak acids, metabolic acidosis may determine an increase in the not-ionized fraction, which, theoretically, enhances drug diffusion through the cell membrane, whereas the reverse phenomenon may apply to drugs that are chemically weak bases [52].

An increase in capillary permeability is primary caused by endothelium damage. Because of plasma extravasation, a large amount of fluids may be accumulated into the interstitium and in anatomical spaces usually fluid-free (third space). This phenomenon affects the distribution of all drugs, especially of those with small distribution volumes.

Perfusion failure and change in distribution volume significantly affect the pharmacokinetic profile of several classes of antibiotics, which play a pivotal role in the pharmacological therapy of primary infections and nosocomial contaminations. Estimation of distribution volume is crucial to calculate appropriate loading and maintenance dose. Several data indicate that the distribution volume of antibacterial drugs most commonly used in patients with SIRS or sepsis, is mainly related with extracellular water, with the exception of fluoroquinolones [55], even though relevant pharmacokinetic differences within the same class of antibacterials (e.g., carbapenems) have been described [88].

Time-dependent antimicrobial agents (e.g., beta-lactams, glycopeptides, oxazolidinones) need to maintain plasma concentrations higher than the minimum inhibitory concentration (MIC), to be more effective $[89,90]$. At the same time, concentration-dependent antimicrobial agents (e.g., aminoglycosides, fluoroquinolones) should be administrated based on the ratio between the area under curve (AUC) and the MIC, and the ratio between plasma-peak concentration $\left(C_{\max }\right)$ and the MIC [89,90]. Therefore, daily determination of antimicrobial plasma concentrations should be performed in critical patients in which the pharmacokinetic determinants (distribution volume, plasma protein, perfusion, kidney/ liver clearance) are so deeply altered.

Reduction in plasma protein radically changes the rate of drug-protein binding. Increased capillary permeability, hemodilution, and kidney failure, all contribute to the diminution of circulating albumin fraction. Moreover, the composition of plasma proteins is altered by the production of acute phase reactant proteins, such as $\alpha 1$-acid glycoprotein, with a profound effect on circulating drugprotein binding [52].

The distribution curve and the biological availability of drugs are also greatly influenced by body mass index [91]. Indeed, obesity can alter both the volume of distribution and the metabolism of antimicrobials, and correction factors based on 'actual' body weight or 'ideal' body weight, depending on the drug, should be employed [91-93]. Infusion dose of sedative drugs should also be accurately adjusted in obese critically ill patients. The sedative effects of propofol and benzodiazepines, such as midazolam and its active metabolite, could be prolonged because of their accumulation in adipose tissues [94].

\section{Half-life modifications}

The half-life of a sedative drug is one of the most important criteria to guide the correct timing of $\mathrm{MV}$ and weaning from ventilatory support. In the critical patient who needs to be continuously sedated for variable lengths of time, the half-life of a sedative molecule is profoundly influenced by the duration of the infusion. The observation of the sustained sedative effect, lasting after the stop of the infusion, moved Hughes et al. in 1992 to develop the concept of context-sensitive half-life (CSHL) $[95,96]$. CSHL should be considered as a 'timeto-recovery' index after a prolonged infusion of a sedative drug, where the context is the duration of the infusion. This index is calculated based on a multicompartment model, but it is not directly related to the half-life of the drug. This pharmacokinetic model is not specific for the altered physiology of a critical patient, but is particularly relevant in this context. Indeed, the accumulation of drugs used for sedation (such as propofol, midazolam, fentanyl) produces a prolongation of the time to recovery, which cannot be predicted using the half-life of the molecule, but it could be estimated from the duration of the infusion, with a large interindividual variability.

\section{CONCLUSIONS}

Pharmacological management of an ICU patient remains a challenge. At present, few evidence-based indications are available. However, the following considerations should always guide the physician who treats complex and critical patients who need multiple drugs: obtain plasma concentrations of drugs whenever possible; consider the altered distribution volume especially when hydrophilic antimicrobial agents are employed; monitor IAP; closely screen hepatic and renal function; ensure an 
appropriate nutritional support. A closer collaboration between the intensivists and the clinical pharmacologists may improve, in the future, the efficacy of care for a critically ill patient.

\section{REFERENCE}

1 Moreno R., Miranda D.R., Matos R., Fevereiro T. Mortality after discharge from intensive care: the impact of organ system failure and nursing workload use at discharge. Intensive Care Med. (2001) 27 999-1004.

2 Rivera-Fernandez R., Nap R., Vazquez-Mata G., Reis Miranda D. Analysis of physiologic alterations in intensive care unit patients and their relationship with mortality. J. Crit. Care (2007) 22 120-128.

3 Bone R.C., Balk R.A., Cerra F.B. et al. Definitions for sepsis and organ failure and guidelines for the use of innovative therapies in sepsis. The ACCP/SCCM Consensus Conference Committee. American College of Chest Physicians/Society of Critical Care Medicine. Chest (1992) 101 1644-1655.

4 Hotchkiss R.S., Karl I.E. The pathophysiology and treatment of sepsis. N. Engl. J. Med. (2003) 348 138-150.

5 Cinel I., Dellinger R.P. Advances in pathogenesis and management of sepsis. Curr. Opin. Infect. Dis. (2007) 20 345-352.

6 Russell J.A. Management of sepsis. N. Engl. J. Med. (2006) 355 1699-1713.

7 Keel M., Trentz O. Pathophysiology of polytrauma. Injury. (2005) 36 691-709.

8 Lever A., Mackenzie I. Sepsis: definition, epidemiology, and diagnosis. BMJ (2007) 335 879-883.

9 Russell J.A., Singer J., Bernard G.R. et al. Changing pattern of organ dysfunction in early human sepsis is related to mortality. Crit. Care Med. (2000) 28 3405-3411.

10 Annane D., Aegerter P., Jars-Guincestre M.C., Guidet B. Current epidemiology of septic shock: the CUB-Rea Network. Am. J. Respir. Crit. Care Med. (2003) 168 165-172.

11 Padkin A., Goldfrad C., Brady A.R., Young D., Black N., Rowan K. Epidemiology of severe sepsis occurring in the first $24 \mathrm{hrs}$ in intensive care units in England, Wales, and Northern Ireland. Crit. Care Med. (2003) 31 2332-2338.

12 Knuefermann P., Nemoto S., Baumgarten G. et al. Cardiac inflammation and innate immunity in septic shock: is there a role for toll-like receptors? Chest (2002) 121 1329-1336.

13 Brown M.A., Jones W.K. NF-kappaB action in sepsis: the innate immune system and the heart. Front Biosci. (2004) 9 12011217.

14 Wanner G.A., Keel M., Steckholzer U., Beier W., Stocker R., Ertel W. Relationship between procalcitonin plasma levels and severity of injury, sepsis, organ failure, and mortality in injured patients. Crit. Care Med. (2000) 28 950-957.

15 Carrol E.D., Thomson A.P., Hart C.A. Procalcitonin as a marker of sepsis. Int. J. Antimicrob. Agents (2002) 20 1-9.

16 Nijsten M.W., Olinga P., The T.H. et al. Procalcitonin behaves as a fast responding acute phase protein in vivo and in vitro. Crit. Care Med. (2000) 28 458-461.
17 Oberhoffer M., Stonans I., Russwurm S. et al. Procalcitonin expression in human peripheral blood mononuclear cells and its modulation by lipopolysaccharides and sepsis-related cytokines in vitro. J. Lab. Clin. Med. (1999) 134 49-55.

18 Joyce C.D., Fiscus R.R., Wang X., Dries D.J., Morris R.C., Prinz R.A. Calcitonin gene-related peptide levels are elevated in patients with sepsis. Surgery (1990) 108 1097-1101.

19 Domenech V.S., Nylen E.S., White J.C. et al. Calcitonin generelated peptide expression in sepsis: postulation of microbial infection-specific response elements within the calcitonin I gene promoter. J. Investig. Med. (2001) 49 514-521.

20 Brain S.D., Grant A.D. Vascular actions of calcitonin generelated peptide and adrenomedullin. Physiol. Rev. (2004) 84 903-934.

21 Springer J., Geppetti P., Fischer A., Groneberg D.A. Calcitonin gene-related peptide as inflammatory mediator. Pulm Pharmacol Ther. (2003) 16 121-130.

22 Philippart F., Cavaillon J.M. Sepsis mediators. Curr. Infect. Dis. Rep. (2007) 9 358-365.

23 Gogos C.A., Drosou E., Bassaris H.P., Skoutelis A. Pro- versus anti-inflammatory cytokine profile in patients with severe sepsis: a marker for prognosis and future therapeutic options. J. Infect. Dis. (2000) 181 176-180.

24 Hotchkiss R.S., Swanson P.E., Freeman B.D. et al. Apoptotic cell death in patients with sepsis, shock, and multiple organ dysfunction. Crit. Care Med. (1999) 27 1230-1251.

25 Le Tulzo Y., Pangault C., Gacouin A. et al. Early circulating lymphocyte apoptosis in human septic shock is associated with poor outcome. Shock (2002) 18 487-494.

26 Guisset O., Dilhuydy M.S., Thiebaut R. et al. Decrease in circulating dendritic cells predicts fatal outcome in septic shock. Intensive Care Med. (2007) 33 148-152.

27 Larche J., Lancel S., Hassoun S.M. et al. Inhibition of mitochondrial permeability transition prevents sepsis-induced myocardial dysfunction and mortality. J. Am. Coll. Cardiol. (2006) 48 377-385.

28 Alonso de Vega J.M., Diaz J., Serrano E., Carbonell L.F. Oxidative stress in critically ill patients with systemic inflammatory response syndrome. Crit. Care Med. (2002) 301782 1786.

29 Matejovic M., Krouzecky A., Rokyta R. Jr et al. Effects of combining inducible nitric oxide synthase inhibitor and radical scavenger during porcine bacteremia. Shock (2007) 27 6168.

30 Matejovic M., Krouzecky A., Radej J. et al. Coagulation and endothelial dysfunction during longterm hyperdynamic porcine bacteremia-effects of selective inducible nitric oxide synthase inhibition. Thromb. Haemost. (2007) 97 304-309.

31 Dellinger R.P. Inflammation and coagulation: implications for the septic patient. Clin. Infect. Dis. (2003) 36 1259-1265.

32 Esmon C.T. The normal role of Activated Protein C in maintaining homeostasis and its relevance to critical illness. Crit. Care (2001) 5 S7-S12.

33 Vincent J.L. Microvascular endothelial dysfunction: a renewed appreciation of sepsis pathophysiology. Crit. Care (2001) 5(Suppl. 2) S1-S5. 
34 Trzeciak S., Dellinger R.P., Parrillo J.E. et al. Early microcirculatory perfusion derangements in patients with severe sepsis and septic shock: relationship to hemodynamics, oxygen transport, and survival. Ann. Emerg. Med. (2007) 49 88-98.

35 Acosta J.A., Yang J.C., Winchell R.J. et al. Lethal injuries and time to death in a level I trauma center. J. Am. Coll. Surg. (1998) 186 528-533.

36 Demetriades D., Murray J., Charalambides K. et al. Trauma fatalities: time and location of hospital deaths. J. Am. Coll. Surg. (2004) 198 20-26.

37 Ni Choileain N., Redmond H.P. The immunological consequences of injury. Surgeon (2006) 4 23-31.

38 Fujishima S., Aikawa N. Neutrophil-mediated tissue injury and its modulation. Intensive Care Med. (1995) 21 277-285.

39 Smith J.A. Neutrophils, host defense, and inflammation: a double-edged sword. J. Leukoc. Biol. (1994) 56 672-686.

40 Laroux F.S., Pavlick K.P., Hines I.N. et al. Role of nitric oxide in inflammation. Acta Physiol. Scand. (2001) 173 113-118.

41 Vercueil A., Grocott M.P., Mythen M.G. Physiology, pharmacology, and rationale for colloid administration for the maintenance of effective hemodynamic stability in critically ill patients. Transfus. Med. Rev. (2005) 19 93-109.

42 Owens T., Babcock A.A., Millward J.M., Toft-Hansen H. Cytokine and chemokine inter-regulation in the inflamed or injured CNS. Brain Res. Brain Res. Rev. (2005) 48 178-184.

43 Babcock A.A., Wirenfeldt M., Holm T. et al. Toll-like receptor 2 signaling in response to brain injury: an innate bridge to neuroinflammation. J. Neurosci. (2006) 26 12826-12837.

44 Uematsu S., Akira S. Toll-like receptors and innate immunity. J. Mol. Med. (2006) 84 712-725.

45 Medzhitov R. Toll-like receptors and innate immunity. Nat Rev Immunol. (2001) 1 135-145.

46 Babcock A.A., Kuziel W.A., Rivest S., Owens T. Chemokine expression by glial cells directs leukocytes to sites of axonal injury in the CNS. J. Neurosci. (2003) 23 7922-7930.

47 Gadient R.A., Otten U.H. Interleukin-6 (IL-6)-a molecule with both beneficial and destructive potentials. Prog. Neurobiol. (1997) 52 379-390.

48 Yong V.W., Power C., Forsyth P., Edwards D.R. Metalloproteinases in biology and pathology of the nervous system. Nat Rev. Neurosci. (2001) 2 502-511.

49 Schmidt O.I., Heyde C.E., Ertel W., Stahel P.F. Closed head injury-an inflammatory disease? Brain Res. Brain Res. Rev. (2005) 48 388-399.

50 Morganti-Kossmann M.C., Rancan M., Stahel P.F., Kossmann T. Inflammatory response in acute traumatic brain injury: a double-edged sword. Curr. Opin. Crit. Care (2002) 8 101-105.

51 Power B.M., Forbes A.M., van Heerden P.V., Ilett K.F. Pharmacokinetics of drugs used in critically ill adults. Clin. Pharmacokinet. (1998) 34 25-56.

52 De Paepe P., Belpaire F.M., Buylaert W.A. Pharmacokinetic and pharmacodynamic considerations when treating patients with sepsis and septic shock. Clin. Pharmacokinet. (2002) 41 1135-1151.

53 Boucher B.A., Wood G.C., Swanson J.M. Pharmacokinetic changes in critical illness. Crit. Care Clin. (2006) 22 255-271.
54 Pea F., Furlanut M. Pharmacokinetic aspects of treating infections in the intensive care unit: focus on drug interactions. Clin. Pharmacokinet. (2001) 40 833-868.

55 Roberts J.A., Lipman J. Antibacterial dosing in intensive care: pharmacokinetics, degree of disease and pharmacodynamics of sepsis. Clin. Pharmacokinet. (2006) 45 755-773.

56 Beale R.J., Hollenberg S.M., Vincent J.L., Parrillo J.E. Vasopressor and inotropic support in septic shock: an evidencebased review. Crit. Care Med. (2004) 32 S455-S465.

57 Ali S., Roberts P.R. Nutrients with immune-modulating effects: what role should they play in the intensive care unit? Curr Opin Anaesthesiol. (2006) 19 132-139.

58 Mansoor O., Breuille D., Bechereau F. et al. Effect of an enteral diet supplemented with a specific blend of amino acid on plasma and muscle protein synthesis in ICU patients. Clin. Nutr. (2007) 26 30-40.

59 Powell-Tuck J. Nutritional interventions in critical illness. Proc. Nutr. Soc. (2007) 66 16-24.

60 Booth C.M., Heyland D.K., Paterson W.G. Gastrointestinal promotility drugs in the critical care setting: a systematic review of the evidence. Crit. Care Med. (2002) 30 1429-1435.

61 Bourgault A.M., Ipe L., Weaver J., Swartz S., O’Dea P.J.. Development of evidence-based guidelines and critical care nurses ' knowledge of enteral feeding. Crit. Care Nurse. (2007) 27, 17-22, 5-9; quiz 30.

62 Abiles J., de la Cruz A.P., Castano J. et al. Oxidative stress is increased in critically ill patients according to antioxidant vitamins intake, independent of severity: a cohort study. Crit. Care (2006) 10 R146.

63 Isakow W., Morrow L.E., Kollef M.H. Probiotics for preventing and treating nosocomial infections: review of current evidence and recommendations. Chest (2007) 132 286-294.

64 Luiking Y.C., Deutz N.E. Exogenous arginine in sepsis. Crit. Care Med. (2007) 35 S557-S563.

65 Zhou M., Martindale R.G. Immune-modulating enteral formulations: optimum components, appropriate patients, and controversial use of arginine in sepsis. Curr. Gastroenterol. Rep. (2007) 9 329-337.

66 Lui F., Sangosanya A., Kaplan L.J. Abdominal compartment syndrome: clinical aspects and monitoring. Crit. Care Clin. (2007) 23 415-433.

67 Stein M., Deegan R., Wood A.J. Long-term exposure to beta 2-receptor agonist specifically desensitizes beta-receptor-mediated venodilation. Clin. Pharmacol. Ther. (1993) 54 187-193.

68 Davis K.A. Ventilator-associated pneumonia: a review. J Intensive Care Med. (2006) 21 211-226.

69 Bolton C.F. Neuromuscular manifestations of critical illness. Muscle Nerve (2005) 32 140-163.

70 Acosta P., Santisbon E., Varon J. The use of positive endexpiratory pressure in mechanical ventilation. Crit. Care Clin. (2007) 23 251-261.

71 Perkins M.W., Dasta J.F., DeHaven B. Physiologic implications of mechanical ventilation on pharmacokinetics. Dicp. (1989) 23 316-323.

72 Maybauer D.M., Talke P.O., Westphal M. et al. Positive endexpiratory pressure ventilation increases extravascular lung 
water due to a decrease in lung lymph flow. Anaesth. Intensive Care (2006) 34 329-333.

73 Hedenstierna G., Lattuada M. Lymphatics and lymph in acute lung injury. Curr. Opin. Crit. Care (2008) 14 31-36.

74 Bernard G.R., Artigas A., Brigham K.L. et al. The AmericanEuropean Consensus Conference on ARDS. Definitions, mechanisms, relevant outcomes, and clinical trial coordination. Am. J. Respir. Crit. Care Med. (1994) 149 818-824.

75 Bernard G.R., Artigas A., Brigham K.L. et al. Report of the American-European Consensus conference on acute respiratory distress syndrome: definitions, mechanisms, relevant outcomes, and clinical trial coordination. Consensus Committee. J. Crit. Care (1994) 9 72-81.

76 Gattinoni L., Vagginelli F., Chiumello D., Taccone P., Carlesso E. Physiologic rationale for ventilator setting in acute lung injury/ acute respiratory distress syndrome patients. Crit. Care Med. (2003) 31 S300-S304.

77 Tasaka S., Hasegawa N., Ishizaka A. Pharmacology of acute lung injury. Pulm. Pharmacol. Ther. (2002) 15 83-95.

78 McKindley D.S., Hanes S., Boucher B.A. Hepatic drug metabolism in critical illness. Pharmacotherapy. (1998) 18 759-778.

79 Boucher B.A., Kuhl D.A., Fabian T.C., Robertson J.T. Effect of neurotrauma on hepatic drug clearance. Clin. Pharmacol. Ther. (1991) 50 487-497.

80 Boucher B.A., Hanes S.D. Pharmacokinetic alterations after severe head injury. Clinical relevance. Clin. Pharmacokinet. (1998) 35 209-221.

81 Dresser G.K., Spence J.D., Bailey D.G. Pharmacokinetic-pharmacodynamic consequences and clinical relevance of cytochrome P450 3A4 inhibition. Clin. Pharmacokinet. (2000) 38 41-57.

82 Steinberg K.P. Stress-related mucosal disease in the critically ill patient: risk factors and strategies to prevent stress-related bleeding in the intensive care unit. Crit. Care Med. (2002) 30 S362-S364.

83 Spina E., Pisani F., Perucca E. Clinically significant pharmacokinetic drug interactions with carbamazepine. An update. Clin. Pharmacokinet. (1996) 31 198-214.

84 Albengres E., Le Louet H., Tillement J.P. Systemic antifungal agents. Drug interactions of clinical significance. Drug Saf. (1998) 18 83-97.
85 Tortorici M.A., Kochanek P.M., Poloyac S.M. Effects of hypothermia on drug disposition, metabolism, and response: A focus of hypothermia-mediated alterations on the cytochrome P450 enzyme system. Crit. Care Med. (2007) 35 2196-2204.

86 Trotman R.L., Williamson J.C., Shoemaker D.M., Salzer W.L. Antibiotic dosing in critically ill adult patients receiving continuous renal replacement therapy. Clin. Infect. Dis. (2005) 41 1159-1166.

87 Kielstein J.T., Czock D., Schopke T. et al. Pharmacokinetics and total elimination of meropenem and vancomycin in intensive care unit patients undergoing extended daily dialysis. Crit. Care Med. (2006) 34 51-56.

88 Novelli A., Adembri C., Livi P., Fallani S., Mazzei T., De Gaudio A.R. Pharmacokinetic evaluation of meropenem and imipenem in critically ill patients with sepsis. Clin. Pharmacokinet. (2005) 44 539-549.

89 Goldberg J., Owens R.C. Jr Optimizing antimicrobial dosing in the critically ill patient. Curr. Opin. Crit. Care (2002) 8 435440.

90 Pea F., Viale P. The antimicrobial therapy puzzle: could pharmacokinetic-pharmacodynamic relationships be helpful in addressing the issue of appropriate pneumonia treatment in critically ill patients? Clin. Infect. Dis. (2006) 42 1764-1771.

91 El-Solh A.A. Clinical approach to the critically ill, morbidly obese patient. Am. J. Respir. Crit. Care Med. (2004) $169557-$ 561.

92 Wurtz R., Itokazu G., Rodvold K. Antimicrobial dosing in obese patients. Clin. Infect. Dis. (1997) 25 112-118.

93 Pai M.P., Bearden D.T. Antimicrobial dosing considerations in obese adult patients. Pharmacotherapy. (2007) 27 10811091.

94 Arcangeli A., Antonelli M., Mignani V., Sandroni C. Sedation in PACU: the role of benzodiazepines. Curr. Drug Targets (2005) 6 745-748.

95 Hughes M.A., Glass P.S., Jacobs J.R. Context-sensitive half-time in multicompartment pharmacokinetic models for intravenous anesthetic drugs. Anesthesiology (1992) 76 334-341.

96 Bailey J.M. Context-sensitive half-times: what are they and how valuable are they in anaesthesiology? Clin. Pharmacokinet. (2002) $41793-799$. 